Running head: INTERPLAY OF MORAL SELF, PROSOCIAL BEHAVIOR, AND EMOTIONS

Emotion understanding and the moral self-concept as motivators of prosocial behavior in middle childhood

Natalie Christner, Carolina Pletti, \& Markus Paulus

Ludwig-Maximilians-Universität München, Munich, Germany

\title{
In press
}

Cognitive Development

Word count $=12126($ text + references $)$

Keywords: Moral self; Prosocial behavior; Positive emotions; Middle childhood

Correspondence concerning this article should be directed to

Natalie Christner

Developmental Psychology

Ludwig-Maximilians-Universität München

Leopoldstr. 13

80802 Munich

Germany

E-mail: natalie.christner@psy.lmu.de

Acknowledgements: For help with data acquisition we are thankful to Lena Griesbeck and Daniel Schneider. This work was supported by an ERC Starting Grant [MORALSELF; No. 679000] to MP. 
INTERPLAY OF MORAL SELF, PROSOCIAL BEHAVIOR, AND EMOTIONS

\begin{abstract}
The moral self-concept reflects the view of oneself in terms of moral behavior and has been proposed to predict actual behavior. Theories also suggest emotions and emotion knowledge to predict prosocial behavior, but the interplay between the moral self-concept and emotions is largely unknown. This interplay is especially important to study in middle childhood, a relevant period for the ontogeny of the moral self-concept and when emotions regarding prosocial behavior are suggested to change. The current study explored the nature of the relation between the moral self-concept, prosocial behavior, and consequential emotions (Experiment 1) or anticipated emotions (Experiment 2) regarding prosocial behavior in 5- to 9-year-olds (together $\mathrm{N}=169$ ). Moreover, we investigated whether emotions mediate the relation between the moral self-concept and prosocial behavior. Overall, the moral self-concept was positively related to prosocial behavior. In addition, emotional consequences as well as anticipated emotions explained age differences in sharing behavior. Moreover, the results hint to an indirect effect of the moral self-concept on sharing behavior through the anticipation of negative feelings when not-sharing. Interestingly, children who first reflected about the affective consequences of prosocial behavior seemed to share more. In line with theories, the results demonstrate that both the moral self-concept and emotions are relevant motivators of prosocial behavior in middle childhood.
\end{abstract}

Keywords: Moral self; Prosocial behavior; Positive emotions; Middle childhood 
INTERPLAY OF MORAL SELF, PROSOCIAL BEHAVIOR, AND EMOTIONS

\section{Emotion understanding and the moral self-concept as motivators of prosocial behavior in}

\section{middle childhood}

Prosocial behavior has numerous beneficial implications for individuals and society. Prosocial behavior contributes to a peaceful coexistence, it is affectively rewarding (Aknin, Van de Vondervoort, \& Hamlin, 2018), and it even leads to positive social and academic outcomes in the long run (Caprara, Barbaranelli, Pastorelli, Bandura, \& Zimbardo, 2000; Flynn, Ehrenreich, Beron, \& Underwood, 2015). Sharing resources is one major aspect of prosocial behavior, since it involves giving up resources for the benefit of others and emerges already in the first years of life (Carpendale, Hammond, \& Atwood, 2013). Understanding the developmental pathway and influencing factors of sharing is therefore an important endeavor.

Research highlighting the role of the moral self or moral identity contributes substantially to this purpose. Originally introduced by Blasi (1983), the concept of moral identity gained increasing attention in social and developmental psychology (for review see Hardy \& Carlo, 2011). Moral identity describes the concept of oneself as a moral person (Aquino \& Reed, 2002). It builds on the integration of morality into the self and is proposed to motivate moral behavior, depending on how self-important this identity is. The term moral self is typically employed to include earlier instances of explicitly reported moral behavior tendencies (Kochanska, Koenig, Barry, Kim, \& Yoon, 2010; Krettenauer, 2013). For the purpose of this study, we use the term moral self-concept for referring to children's view of themselves with regard to moral behaviors and to include both explicit as well as implicit facets.

A separate line of theories emphasizes the role of emotions for prosocial behavior (e.g., Eisenberg, 2000; Lemerise \& Arsenio, 2000). Emotions are for example proposed to signal the personal relevance of events, to influence the prioritization of behavior alternatives, and thus to explain individual differences in behavioral tendencies. Consequently, developmental research 
INTERPLAY OF MORAL SELF, PROSOCIAL BEHAVIOR, AND EMOTIONS

has tried to clarify the emotional correlates and mechanisms related to prosocial behavior (e.g., Denham, 1986; Ongley \& Malti, 2014; Sabato \& Kogut, 2019).

The current study consists of two experiments that aimed at assessing the development of the interrelation between the moral self-concept, consequential and anticipated emotions, and prosocial action in middle childhood. In the following, we first review research on the moral self-concept. Then, we focus on the role of emotions in prosocial behavior. Finally, we introduce our research question and experimental approach in detail.

\section{Moral self-concept and prosocial behavior}

The moral self-concept is assumed to motivate moral behavior from early on (Blasi, 1983). However, while a variety of studies reported the moral self-concept as a predictor of prosocial behavior in adolescence (e.g., Hardy, Walker, Olsen, Woodbury, \& Hickman, 2014) and adulthood (for review see Hertz \& Krettenauer, 2016), only little research addressed the emergence of this relation in childhood. Kochanska (2002) suggests that from around four years, children have an internally consistent moral self-concept that reflects children's view of themselves as a "good" person based on their history of compliance with parental rules. This self-concept is supposed to regulate future moral behavior. Indeed, Kochanska (2002) demonstrated that around 4.5 years, boys' moral self-concept correlated positively with rule internalization. Children's moral self-concept at 5.5 years predicted competent social functioning as rated by parents and teachers at 6.5 years (Kochanska et al., 2010). Sengsavang and Krettenauer (2015) explored two dimensions of the moral self-concept, namely preference for prosocial behavior and avoidance of antisocial behavior. The moral self-concept operationalized accordingly related negatively with aggressive behavior as reported by parents in 4- to 12-year-olds. Research on the relation between the moral self-concept and prosocial behavior in middle childhood is, however, absent. Previous studies on the moral self-concept in middle childhood investigated relations with antisocial behavior or moral emotions 
INTERPLAY OF MORAL SELF, PROSOCIAL BEHAVIOR, AND EMOTIONS

(Krettenauer, Campbell, \& Hertz, 2013; Sengsavang \& Krettenauer, 2015), while research on the relation with competent social functioning or prosocial behavior focused on younger children or adolescents (Johnston \& Krettenauer, 2011; Kochanska et al., 2010). Yet, middle childhood is deemed to be an important period for the ontogeny of the moral self (Kingsford, Hawes, \& de Rosnay, 2018). Cognitive advances allow for self-evaluative processes and higher-order representations of oneself (Harter, 2007). From a theoretical perspective, the capacity to withhold egoistic desires in the face of opposing moral desires is also supposed to show a pronounced development around the age of 7-8 (Krettenauer, 2013). Around that age, the moral self-concept is therefore suggested to reflect the ability of prioritizing moral concerns over preferred others. One aim of the current study is therefore to close this gap in the literature and investigate the relation of the moral self-concept and prosocial behavior in middle childhood.

Prosocial behavior describes behavior that benefits another person without directly benefitting the actor him-/herself (Paulus, 2014). From around 1 to 2 years of age, children show early forms of prosocial behavior such as comforting others who are in distress and instrumentally helping others (for review see Brownell, 2013). Developmental research typically differentiates between three types of prosocial behavior, namely sharing, helping, and comforting. These behaviors may result from different motives and seem to be not consistently correlated in early childhood (Dunfield, Kuhlmeier, O’Connell, \& Kelley, 2011; Paulus, 2014). With respect to sharing, children from 3 years on appreciate equality during resource distribution and expect this principle from others (e.g., Elenbaas, 2019; Rakoczy, Kaufmann, \& Lohse, 2016). Nevertheless, they tend to favor themselves in sharing situations up to around 7 years. With increasing age, children typically share equally and sharing equally becomes affectively rewarding (Kogut, 2012; Smith, Blake, \& Harris, 2013). Middle childhood is 
therefore an interesting period to examine factors underlying these developmental changes in sharing behavior.

Previous research differentiated between an explicit and implicit moral self-concept based on dual process models of cognition (Lapsley \& Hill, 2008; Zaki \& Mitchell, 2013). The explicit moral self-concept is supposed to reflect cognitively controlled processes and is typically measured through questionnaires or interviews (e.g., Aquino \& Reed, 2002; Kochanska, 2002). The implicit moral self-concept is assumed to reflect more automatic processes and is typically measured through an Implicit Association Test (IAT; e.g., Perugini \& Leone, 2009; Pletti, Decety, \& Paulus, 2019). However, both mechanisms might be at work simultaneously. Self-reported motives seem to reflect cognitive constructs, while implicit motives seem to be based on the inherent pleasure of actions (McClelland, Koestner, \& Weinberger, 1989). Consequently, the current study included explicit and implicit measures of the moral self in children.

\section{Consequential emotions and anticipated emotional consequences of prosocial behavior}

When considering emotions regarding prosocial behavior, it is important to distinguish between emotional consequences of prosocial behavior and anticipated emotions. Even though predictions about future affective states originate from actual affective experiences in the past, they tend to differ (Dunn et al., 2008; Wilson \& Gilbert, 2005). Moreover, Malti and Krettenauer (2013) suggested that the relative importance of consequential compared to anticipated emotions might change with age. While younger children might rely more on consequential emotions that are linked with behavior through associative learning, older children might rely more on anticipated emotions that require perspective-taking skills. This is particularly important when identifying the emotions related to the moral self-concept, because the self-relevance of an action might manifests itself more in the one type of emotions than the other. In the following, we will review two separate lines of research investigating the emotional 
INTERPLAY OF MORAL SELF, PROSOCIAL BEHAVIOR, AND EMOTIONS

consequences of prosocial behavior on the one hand and anticipated emotions regarding prosocial behavior on the other hand.

Let us first consider the emotional consequences of prosocial behavior. Next to the positive effects for the beneficiary, prosocial actions are proposed to lead to greater happiness for the benefactor as well (Aknin et al., 2018; Bierhoff, 2002). Empirical studies supported this link: Adults felt happier after spending money on others than after spending money on themselves (Dunn et al., 2008). From the age of 9-10 years on, children reported higher satisfaction after sharing half of some candies, consistent with a fairness norm, than after sharing less than half (Kogut, 2012). Likewise, toddlers and preschoolers display positive emotions when acting prosocially (Aknin, Hamlin, \& Dunn, 2012; Ross, 2017). Importantly, this pleasurable experience might increase prosocial behavior in the future, based on motivational theories on action selection (De Wit \& Dickinson, 2009). According to these, prosocial behavior would be associated with the positive emotional state, and thus the positive outcome might directly trigger prosocial behavior in the future. That means, the better a person will feel after acting prosocially, the more likely she will engage in future prosocial action.

A separate line of research focuses on emotions that people anticipate when acting prosocially. Research on expected emotions in hypothetical scenarios typically report that from around school-age, 6 to 8 years, children expect positive emotions to follow prosocial behavior and negative emotions to follow antisocial behavior (e.g., Keller, Lourenço, Malti, \& Saalbach, 2003; Nunner-Winkler \& Sodian, 1988). Interestingly, Paulus and Moore (2017) demonstrated that 3- to 6-year-old preschoolers anticipate to feel better after acting generously. These emotion anticipations might directly trigger prosocial behavior. Based on ideomotor theory of action control, anticipated consequences of actions guide action control. In particular, recent theories suggest that anticipated emotional consequences are crucial for behavior control (Eder, Rothermund, De Houwer, \& Hommel, 2015; Ridderinkhof, 2017). Applying this line of thought 
INTERPLAY OF MORAL SELF, PROSOCIAL BEHAVIOR, AND EMOTIONS

to our research question, the more positive a person will anticipate to feel after acting prosocially and the more negative after omitting prosocial action, the more likely future prosocial action. Indeed, preschoolers' anticipated emotions after acting generously influenced future generous behavior (Paulus \& Moore, 2017). Indeed, a meta-analysis highlights that anticipated emotions and prosocial behavior are related across childhood (Malti \& Krettenauer, 2013). In sum, research thus supports a link between prosocial behavior and both consequential and anticipated positive feelings for the benefactor.

Previous studies on consequential and anticipated emotions differed in methodological aspects such as the abstractness of the described behavior (concrete behavior vs. hypothetical scenario) and the comparability between participants (emotion about same behavior for all participants vs. emotion about self-chosen behavior). Paulus and Moore (2017) revealed that 3to 6-year-olds anticipate to feel happy after sharing and less happy after not-sharing in a concrete scenario. Other studies on hypothetical scenarios revealed negative emotion attributions about not acting prosocially from around 7-8 years (Nunner-Winkler \& Sodian, 1988). Consequential emotions following self-chosen behavior appeared to be positive after sharing half only from nine years on (Kogut, 2012). These findings thus suggests that children first expect to feel positive after sharing, while negative emotions about not-sharing increase with age. We planned to extend this literature by comparing anticipated and consequential emotions in experimental designs in an age, when emotions are supposed to undergo a profound change. The study examined emotions as one mechanism underlying developmental changes in sharing behavior. In particular, we investigated whether increasing emotional relevance of sharing and not-sharing can explain increased sharing behavior with age.

\section{Interrelations between the moral self, emotions, and prosocial behavior}

Starting from these bases, the current study aimed to integrate research on moral emotions, the moral self-concept, and prosocial behavior. One question concerned the nature of the relation 
between the moral self-concept and prosocial behavior, that means, how do these processes relate to each other. Emotions are a promising candidate in this context due to their evaluative and motivational component (Scherer, 1987): Emotions signal the significance of an event and motivate the direction of future action. By bringing research on emotions together with research on the moral self-concept, the current study aimed at investigating whether emotions mediate the relation between moral self-concept and behavior. In other words: Could the "warm glow" that has been shown to follow from prosocial behavior (Dunn et al., 2008) be related to the moral self-concept (e.g., by noting that one lives up to one's own standard) (Experiment 1)? Or could the anticipation of positive emotions that has been shown for sharing behavior (Paulus \& Moore, 2017) be related to the moral self-concept (Experiment 2)?

According to self-determination theory, acting according to one's values is intrinsically motivating and pleasurable (Ryan \& Deci, 2000). Based on that, prosocial actions should be intrinsically motivating for people with strong internalized moral values, as reflected in their strong moral self-concept, and should raise positive feelings. Since anticipated emotions are constructed based on previous experiences, we would likewise expect that people with a strong moral self-concept anticipate positive feelings when they expect to act prosocially. This idea is supported by research showing that children's moral self-concept and emotions following a hypothetical immoral action are related (Krettenauer et al., 2013). We thus expected that children with a strong moral self-concept both feel better after acting prosocially and anticipate to feel better after such a behavior.

Importantly, we expect these emotions regarding prosocial behavior in turn to be linked to actual behavior. On the one hand, motivational theories on action selection suggest that the experience following a behavior gets directly associated with the behavior and thus influences the likelihood of this behavior in the future (De Wit \& Dickinson, 2009). On the other hand, ideomotor theory of action control suggests that anticipated emotional consequences are crucial 
for behavior control (Eder et al., 2015; Ridderinkhof, 2017). We extend previous research by differentiating between these two accounts in the domain of prosocial behavior and, most importantly, by investigating the link to the moral self-concept. We thus aimed to investigate, whether the relation between the moral self-concept and prosocial behavior is mediated by consequential or anticipated emotions regarding prosocial behavior.

\section{Current studies}

To address our research question, we assessed preschool and school-aged children, since prosocial behavior seems to become emotionally relevant especially in middle childhood: Emotions regarding moral transgressions shift from positive to negative (Nunner-Winkler \& Sodian, 1988), and children within these ages show increasing pleasure from actual prosocial behavior (Kogut, 2012). Additionally, this developmental period has been suggested to be an important phase for the development of the moral self-concept (Kingsford et al., 2018; Krettenauer, 2013). In both experiments, participants completed a sharing task in which they had the opportunity to allocate items to themselves or others. We decided to focus on sharing, since prosocial behavior manifests itself often in distributing resources and the assessment of sharing behavior is comparable across age groups using the same method (e.g., Smith, Blake, \& Harris, 2013). Next, we assessed the emotional relevance of sharing. For that purpose, participants in Experiment 1 were requested to share half or none of the items and to report their emotional state afterwards. Participants in Experiment 2 were asked to imagine sharing half or none of the items and to report their anticipated emotional state. Lastly, we assessed the explicit and implicit moral self-concept (only explicit self-concept in Experiment 2) by means of an established puppet interview (e.g., Reese et al., 2007; Sengsavang \& Krettenauer, 2015) and an implicit association test (IAT) similar to IATs that have been used with preschool children in previous work (Cvencek, Greenwald, \& Meltzoff, 2011). We addressed our research question 
INTERPLAY OF MORAL SELF, PROSOCIAL BEHAVIOR, AND EMOTIONS

in two experiments. Experiment 1 examined the role of emotions following sharing, Experiment 2 addressed the role of anticipated emotions. In order to be able to compare consequential and anticipated emotions, we kept both experimental procedures similar except for order and details of the emotion rating task (see below). Analyses across experiments thus allowed us to compare both types of emotions and to address relations between variables that were assessed equally in both experiments in a larger sample.

We hypothesized that the moral self-concept predicts prosocial behavior, based on theories stressing the motivational mechanism of moral identity (Aquino \& Reed, 2002; Blasi, 1983). Second, the stronger the moral self-concept, the better children would feel after sharing compared to not-sharing (Experiment 1). Likewise, the stronger the moral self-concept, the better children anticipate to feel after sharing compared to not-sharing (Experiment 2). These hypotheses are based on self-determination theory, suggesting that actions, which are consistent with one's values (i.e. moral actions when the moral self-concept is strong), are intrinsically motivating and lead to greater well-being (Ryan \& Deci, 2000). Third, we had two hypotheses regarding the relation of the emotional significance of sharing and prosocial behavior. Based on theories proposing that the experiences following a behavior guide future action (De Wit \& Dickinson, 2009), we hypothesized that consequential emotions relate to prosocial behavior (Experiment 1), meaning the more positive participants feel after sharing compared to notsharing, the more items they decide to share themselves. Based on the recent ideomotor approaches to emotion and action control (e.g., Eder et al., 2015; Ridderinkhof, 2017), we hypothesized that anticipated emotions relate to prosocial behavior (Experiment 2). Finally, in our mediation hypothesis, we investigated whether either consequential or anticipated emotions mediate the relation between moral self-concept and sharing behavior.

Regarding developmental changes, we expected preschoolers to rather favor themselves when sharing resources and school-aged children to share on average half (Smith et al., 2013). 
We hypothesized that this behavioral development can be explained by age differences in emotions, as we expected both consequential and anticipated emotions about not-sharing to become more negative from preschool to school-aged children based on increasing moral motivation (Nunner-Winkler, 2007) or more differentiated outcome expectancies (Krettenauer, 2012). At the same time, we expected the relation between emotions (consequential and anticipated) and prosocial behavior to be stable across age groups based on the notion that emotion attributions reflect behavioral dispositions (Malti \& Krettenauer, 2013). Finally, we hypothesized the relations of the moral self-concept with emotions (consequential and anticipated) and behavior to increase with age based on increasing experience with own behavior and others' reactions to that (Brummelman \& Thomaes, 2017) and based on an advanced self-concept (cf. Harter, 2007). These advancements cause a more realistic and differentiated self-evaluation, which we hypothesize results in increasing relations with the moral self-concept between 5 and 9 years. We expected similar effects for consequential and anticipated emotions based on the assumption that anticipated emotions stem from previous consequential emotions. At the same time, we aimed to clarify whether children's developmental pathway differs between consequential and anticipated emotions.

\section{Experiment 1}

\section{Method}

\section{Participants}

The final sample included 86 children. The sample comprised a group of preschool children (n $=42, M=6 ; 4$ (years;months), $S D=3.84$ months, range: $5 ; 9-6 ; 11 ; 22$ female) and a group of school-aged children ( $\mathrm{n}=44, M=8 ; 5, S D=2.89$ months, range: $8 ; 1-8 ; 11 ; 19$ female). We determined the sample size based on a power analysis using G*Power (Erdfelder, Faul, \& Buchner, 1996). In order to detect an effect size of $f^{2}=0.11$ in a multiple linear regression with 
INTERPLAY OF MORAL SELF, PROSOCIAL BEHAVIOR, AND EMOTIONS

$\alpha=0.05$ and a power level of 0.80 , a sample size of 74 participants is necessary. We estimated this effect size for the relation of the moral self-concept and prosocial behavior based on the results by Kochanska et al. (2010) on adaptive functioning. In addition, a sample size of 78 seems to be sufficient to detect medium-sized paths in a mediation model using percentile bootstrapping with the same alpha and power level (Fritz \& MacKinnon, 2007). We excluded one additional 6-year-old and one additional 8-year-old child due to parental interference or missing data. Participants were typically developing children living in the surroundings of a large European city. Children's caregivers provided informed written consent for participation. The university's ethics committee had the experiment approved. Children received a present for participation.

\section{Procedure}

We examined all children individually in the university laboratory or the child's preschool. Sessions were videotaped. Children first completed the sharing task, next they completed the implicit and finally the explicit moral self-concept measure. The whole procedure lasted around 30 minutes.

\section{Measures}

Sharing task. The sharing task entailed three conditions for assessing sharing behavior as well as associated emotional states: Free Sharing, Sharing Half, and Sharing Nothing. Free Sharing served to assess children's spontaneous prosocial behavior, while Sharing Half and Sharing Nothing served to assess children's emotional significance of sharing. We decided to rely on these three trial types rather than children's emotional state after their free sharing decision, because this was confounded with the amount they shared. We could have therefore not investigated the relation of the moral self-concept to sharing behavior and emotions separately. Asking for a specific action (sharing half, sharing nothing) reduced the autonomy of participants, but this factor was orthogonal to the sharing condition. Importantly, this procedure 
INTERPLAY OF MORAL SELF, PROSOCIAL BEHAVIOR, AND EMOTIONS

thus allowed to compare the emotional relevance of sharing between participants in an experimentally controlled design.

At the beginning, the child selected the two out of three types of items that he/she liked most (e.g. stickers and erasers). These served as resources during the entire sharing task. Every sharing condition (Free Sharing, Sharing Half, Sharing Nothing) was presented with each selected type of items, resulting in two trials per condition (e.g. animal stickers and erasers in each condition). Within each trial, the child received four identical items (e.g. four cow stickers or four pineapple-shaped erasers). The introduction of the first trial (Free Sharing) was as follows: "All these stickers/erasers now belong to you, they are yours. If you want, you can share these items with another child. We are collecting toys for Niko/Nina (gender-matched, showing photo of the child and donation box) who has no stickers/erasers. So, you can now share one, two, three, four, or none of the items with Niko/Nina, and pack the remaining ones into this envelope and take them home (envelop and box placed at the same distance in front of the child)." Once the child had allocated all items, the experimenter verbally stated the distribution and asked: "How do you feel about that?" The child rated his/her emotional state regarding the distribution as described below. In the Sharing Half and Sharing Nothing trials, the experimenter also first allocated all items to the child, stated that they belong to him/her, and then expressed how the child will distribute them: "You will now share X items and keep Y items for yourself." Subsequently, the child implemented the distribution and rated his/her emotional state. The sharing task always started with Free Sharing trials in order to prevent anchoring effects based on the proposed amounts of the predetermined trials. We randomized Sharing Half and Sharing Nothing trials afterwards.

Emotion rating. The emotion rating assessment was adopted from previous developmental studies (e.g., Paulus \& Moore, 2017; Williams, O’Driscoll, \& Moore, 2014). After each trial, participants rated their emotional state regarding the sharing decision by means of the Facial 
Affective Scale (Perrott, Goodenough, \& Champion, 2004). The pictorial rating scale consists of nine emotionally expressive faces, ranging from extremely sad (1) to extremely happy (9). Children first were familiarized with the scale and requested to indicate four emotions to ensure that they were competent in using it. Following previous research, we computed difference scores by subtracting the mean emotion after Sharing Nothing from the mean emotion after Sharing Half individually for each subject. Thereby, a response tendency in any direction is cancelled out, resulting in the relative emotional significance of sharing. The more positive the emotional differentiation score, the more positive emotions participants reported after Sharing Half versus Sharing Nothing.

Participants rated at the beginning of the session their current emotional state. Initially, we thought to account for the participant's mood. Yet, since the question about the emotional state after each trial directly referred to the decision and not the general feeling at that moment, we decided to disregard this emotion rating in further analyses.

Explicit moral self-concept. The self-concept assessment builds on previous developmental studies employing puppet interviews (e.g., Kochanska, 2002). More specifically, we relied on a short version of a child-friendly moral self-concept interview that we had developed (*reference deleted for blind review*) by adapting the Children's Moral Self Puppet Scale (CMSPS) by Sengsavang and Krettenauer (2015), and the self-concept measures by Marsh, Ellis, and Craven (2002). In each trial, the child saw a pair of identical puppets sitting side by side, played by the experimenter. One puppet expressed a preference for prosocial behavior, while the other puppet said the opposite (e.g. "I like to share my pencils." - "I don't like to share my pencils."). Next, the experimenter asked the child: "What about you?" The child answered by stating which behavior he/she prefers and thus which puppet he/she is more alike. The experimenter asked subsequently: “Are you a little or a lot like this puppet?” Replies ranged on a 5-point scale from a lot like the non-prosocial puppet (1) to a lot like the prosocial puppet 
(5). In case a child expressed that he/she is in the middle of both puppets, the answer received a score of three. The final Puppet Interview comprised 16 items overall, presented in mixed order. Nine items addressed the preference of prosocial behavior, with three items tapping into the domains of helping, sharing, and consoling each. Additionally, four items on the verbal and physical ability self-concept (Marsh et al., 2002) served as distractors. Appendix A provides a list of all items. The order as well as the side of the puppet stating the positive/negative statement was counterbalanced. Across trials, three different pairs of identical puppets alternated while their order was counterbalanced.

We decided to focus on the subset of sharing items in our main analyses, due to the focus on sharing in our behavioral task. The mean across these items reflects the explicit moral self-concept score.

Implicit moral self-concept. We assessed the implicit moral self-concept by use of an Implicit Association Test (IAT) based on Perugini and Leone (2009). Following previous work (e.g., Cvencek et al., 2011), we constructed a child-friendly version of the IAT. Simplified words guaranteed children's understanding of categories and items. The categories Moral and Immoral were replaced by Good and Bad, consisting of the items "helping, sharing, consoling", and "hitting, pushing, stealing", respectively. By composing the Good and Bad category of prosocial and antisocial words, we ensured to assess the moral self-concept rather than implicit self-esteem. The categories Self (Items: I, my, myself) and Others (Items: others, they, them) remained the same as in the IAT by Perugini and Leone (2009). Further adaptations included auditory instead of written stimuli, color-coded response buttons, and reduced number of trials. The exact procedure is described in Appendix B. For calculating a final score of implicit association, we applied the improved scoring algorithm by Greenwald, Nosek, and Banaji (2003). 
Control variables. In order to control for effects of Social Desirability, we included three items regarding socially desirable behaviors from the CMSPS (Sengsavang \& Krettenauer, 2015) in our puppet interview (e.g. "I always say 'please' when asking for something."). The proportion of items answered in the most socially desirable way counted as social desirability response bias.

\section{Results}

Children shared on average 1.72 out of the four items in the free sharing trials $(S D=0.86)$. This behavior was comparable in younger $(M=1.56, S D=0.89)$ and older children $(M=1.86, S D$ $=0.80), t(84)=-1.66, p=.100, \mathrm{~d}=0.36$. One-sample $\mathrm{t}$-tests comparing sharing behavior against equal distribution (2 items) revealed that younger children shared significantly less than half, $t(41)=-3.20, p=.003, d=0.49$, while older children shared around half, $t(43)=-1.13, p=$ $.266, d=0.17$. The explicit moral self-concept was stronger in younger $(M=4.54, S D=0.57)$ than older children $(M=4.17, S D=0.76), t(80.07)=2.53, p=.013, d=0.54$. Descriptive statistics of the emotion ratings are depicted in Figure 1. The emotion difference between Sharing Half and Sharing Nothing was greater in older $(M=1.98, S D=2.37)$ than younger children $(M=0.05, S D=1.53), t(73.90)=4.51, p<.001, d=0.96$. While emotions after Sharing Half and Sharing Nothing differed in older children, $t(43)=5.56, p<.001, d=1.11$, they did not differ in younger children, $t(41)=0.23, p=.821, d=0.04$.

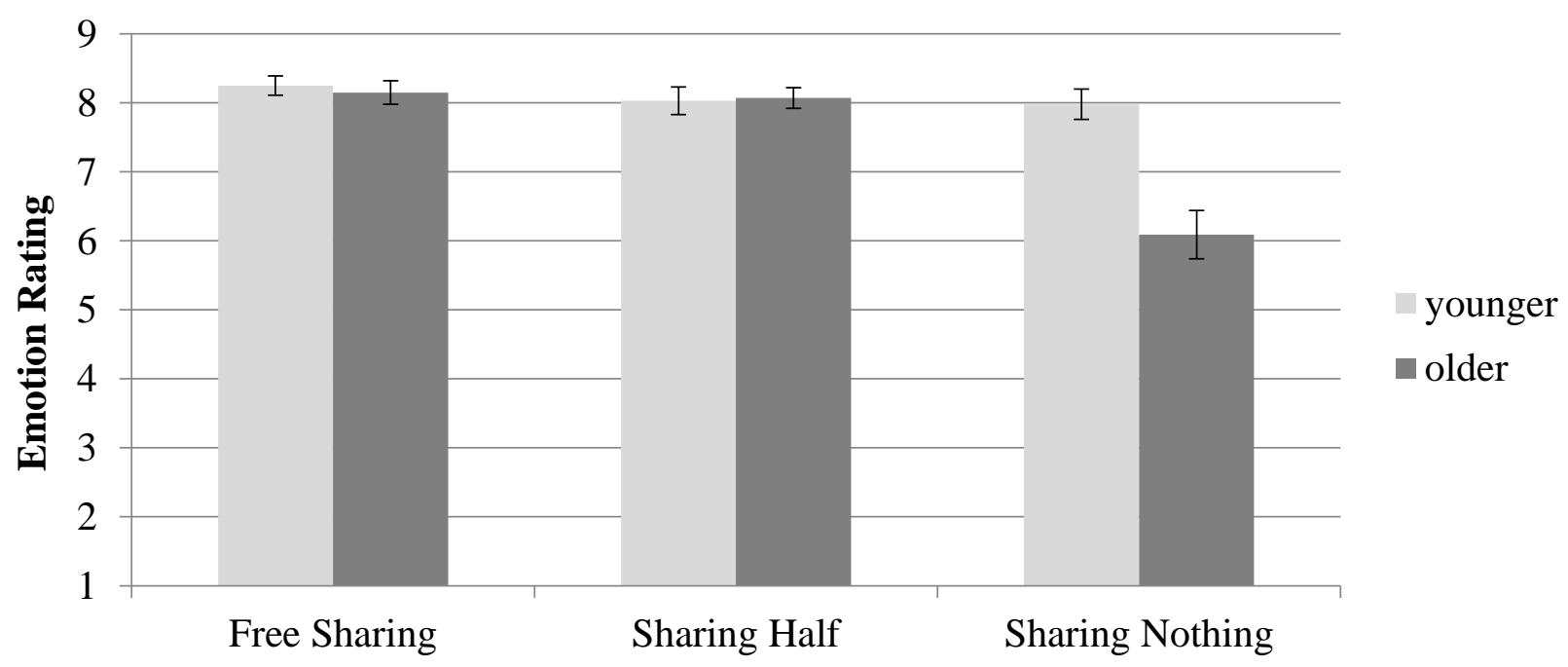


INTERPLAY OF MORAL SELF, PROSOCIAL BEHAVIOR, AND EMOTIONS

Figure 1. Mean emotion ratings after Free Sharing, Sharing Half, and Sharing Nothing trials divided by Age Group. Error bars represent standard errors of the means.

Table 1 depicts a full correlation matrix using Pearson correlation. In order to address our hypotheses on relations between the variables, we computed hierarchical regression analyses. In Step 1, we entered control variables (e.g., social desirable response bias) and all main effects. In Step 2, we entered relevant two-way interactions. Results of all regression analyses are presented in Table 2 .

In order to address our first hypothesis, the relation between the moral self-concept and behavior, we computed two hierarchical linear regressions: one regarding the explicit and one regarding the implicit self-concept. In the model regarding the explicit moral self-concept, only age group significantly predicted sharing behavior, that means, older children shared more than younger children. In the model regarding the implicit moral self-concept, no variable significantly predicted sharing behavior. Age group did interact neither with the explicit nor the implicit self-concept in predicting sharing behavior.

Next, we addressed the relation between the moral self-concept and emotions. Again, only age group but no moral self-concept measure predicted the emotion differentiation, that means, emotions of older children differed more between sharing and not-sharing than emotions of younger children. Age group and the explicit or implicit moral self-concept did not interact in predicting the emotion differentiation.

Regarding the relation between emotions and behavior, regression analyses revealed a strong effect of emotion differentiation on sharing behavior, which was not explained by age differences. That means, the better children felt after sharing versus not-sharing, the more they actually shared when they had the chance to. Age group and the emotion differentiation did not interact in predicting sharing behavior. 
Since we did not find the relevant predictions of sharing behavior and emotion differentiation from the moral self-concept, we omitted the planned mediation analysis to test emotions as a mediator between the self-concept and behavior. In order to investigate whether emotion differentiation explains the age effect on sharing behavior, we computed a mediation analysis. Correlation analyses revealed a significant relation between age group and emotion differentiation as well as between emotion differentiation and sharing behavior, and regression analyses suggested the age effect on sharing behavior to vanish when controlling for emotion differentiation. To test the significance of the indirect effect, we used a percentile bootstrapping approach with 10000 samples using the R-package lavaan (Rosseel, 2012). The confidence interval was above zero, 95\% CI [0.10, 0.46], meaning emotion differentiation significantly mediated the relation between age and sharing behavior. That means older children shared on average more based on the affective benefits of sharing for them.

Table 1

Full correlation matrix of all variables in Experiment 1.

\begin{tabular}{cccccccc}
\hline & $\mathbf{1}$ & $\mathbf{2}$ & $\mathbf{3}$ & $\mathbf{4}$ & $\mathbf{5}$ & $\mathbf{6}$ & $\mathbf{7}$ \\
\hline $\mathbf{2}$ & -0.13 & - & & & & & \\
$\mathbf{3}$ & 0.11 & -0.01 & - & & & & \\
$\mathbf{4}$ & -0.02 & 0.09 & $0.36^{* * *}$ & - & & & \\
$\mathbf{5}$ & 0.07 & 0.08 & 0.07 & $0.32^{* *}$ & - & & \\
$\mathbf{6}$ & 0.06 & -0.05 & $-0.33^{* *}$ & $-0.86^{* * *}$ & $0.21^{*}$ & - & \\
$\mathbf{7}$ & $0.34 * *$ & -0.13 & 0.02 & -0.18 & 0.01 & $0.19^{+}$ & \\
$\mathbf{8}$ & $-0.26^{*}$ & 0.04 & $0.18^{+}$ & $0.44^{* * *}$ & 0.02 & $-0.44^{* * *}$ & $-0.29 * *$ \\
\hline
\end{tabular}

Note. (1) Explicit moral self-concept: Sharing; (2) Implicit moral self-concept; (3) Free sharing behavior; (4) Mean emotion differentiation; (5) Mean emotion after sharing half; (6) Mean emotion after sharing nothing; (7) Social desirable response tendency; (8) Age Group [0: younger; 1 : older]. $* * * \mathrm{p}<.001 ; * * \mathrm{p}<.01 ; * \mathrm{p}<.05 ;{ }^{+} \mathrm{p}<.1$.

Table 2 
Hierarchical linear regressions of the moral self-concept (explicit, implicit) and emotion differentiation on free sharing behavior as well as of the moral self-concept on emotion differentiation. For the models, $R^{2}$ and p-values are reported; for the individual predictors, standardized beta-values and p-values are reported.

\begin{tabular}{|c|c|c|c|c|c|c|c|c|}
\hline & \multicolumn{4}{|c|}{ Sharing Behavior } & \multicolumn{4}{|c|}{ Emotion Differentiation } \\
\hline & \multicolumn{2}{|c|}{ Step 1} & \multicolumn{2}{|c|}{ Step 2} & \multicolumn{2}{|c|}{ Step 1} & \multicolumn{2}{|c|}{ Step 2} \\
\hline & $\beta$ & $p$ & $\beta$ & $p$ & $\beta$ & $p$ & $\beta$ & $p$ \\
\hline Social Desirability & .03 & .825 & & & -.09 & .411 & & \\
\hline Explicit Self-Con. & .17 & .152 & & & .13 & .243 & & \\
\hline Age Group & .23 & .046 & & & .45 & .000 & & \\
\hline Expl. SC x Age Group & & & .55 & .450 & & & -.07 & .922 \\
\hline $\mathrm{R}^{2}, \mathrm{p}$ & 0.06 & .160 & .07 & .221 & 0.21 & .000 & 0.21 & .001 \\
\hline Implicit Self-Con. & -.02 & .851 & & & .07 & .469 & & \\
\hline Age Group & .18 & .101 & & & .44 & .000 & & \\
\hline Impl. SC x Age Group & & & .05 & .791 & & & .14 & .405 \\
\hline $\mathrm{R}^{2}, \mathrm{p}$ & 0.03 & .256 & .03 & .427 & 0.20 & .000 & 0.20 & .000 \\
\hline Emotion Different. & .35 & .003 & & & & & & \\
\hline Age Group & .03 & .825 & & & & & & \\
\hline Em. Diff. x Age Group & & & -.02 & .947 & & & & \\
\hline $\mathrm{R}^{2}, \mathrm{p}$ & 0.13 & .003 & .13 & .009 & & & & \\
\hline
\end{tabular}

\section{Exploratory analyses}

In order to investigate descriptively whether children's reported emotions following the requested trials are comparable to children's emotions following free sharing decisions, we examined children's first free sharing decision in more detail and split children based on this decision. In particular, we split children into groups of children who shared nothing ore less than half (0-1 items; younger: $n=19$; older: $n=12)$, children who shared half ( 2 items; younger: $n=18$; older: $n=23)$, and children who shared more than half (3-4 items; younger: $n=5$; older: $n=9$ ). Figure 2 displays the emotion ratings for the three trial types (First Free Sharing, Sharing Half, Sharing Nothing) for each age group. For younger children, emotion 
ratings in all three groups were comparable for the three trial types. For older children, emotion ratings depended on children's own sharing behavior, but the emotion ratings about freely chosen and the respective requested decisions (Sharing Half, Sharing Nothing) were similar. Children who decided to share less than half reported similar emotion ratings in the tree trial types. Their emotion pattern therefore resembles the pattern of younger children. Children who decided to share half or more than half felt about that similarly to when they were requested to share half (but better than when they were requested to share nothing).

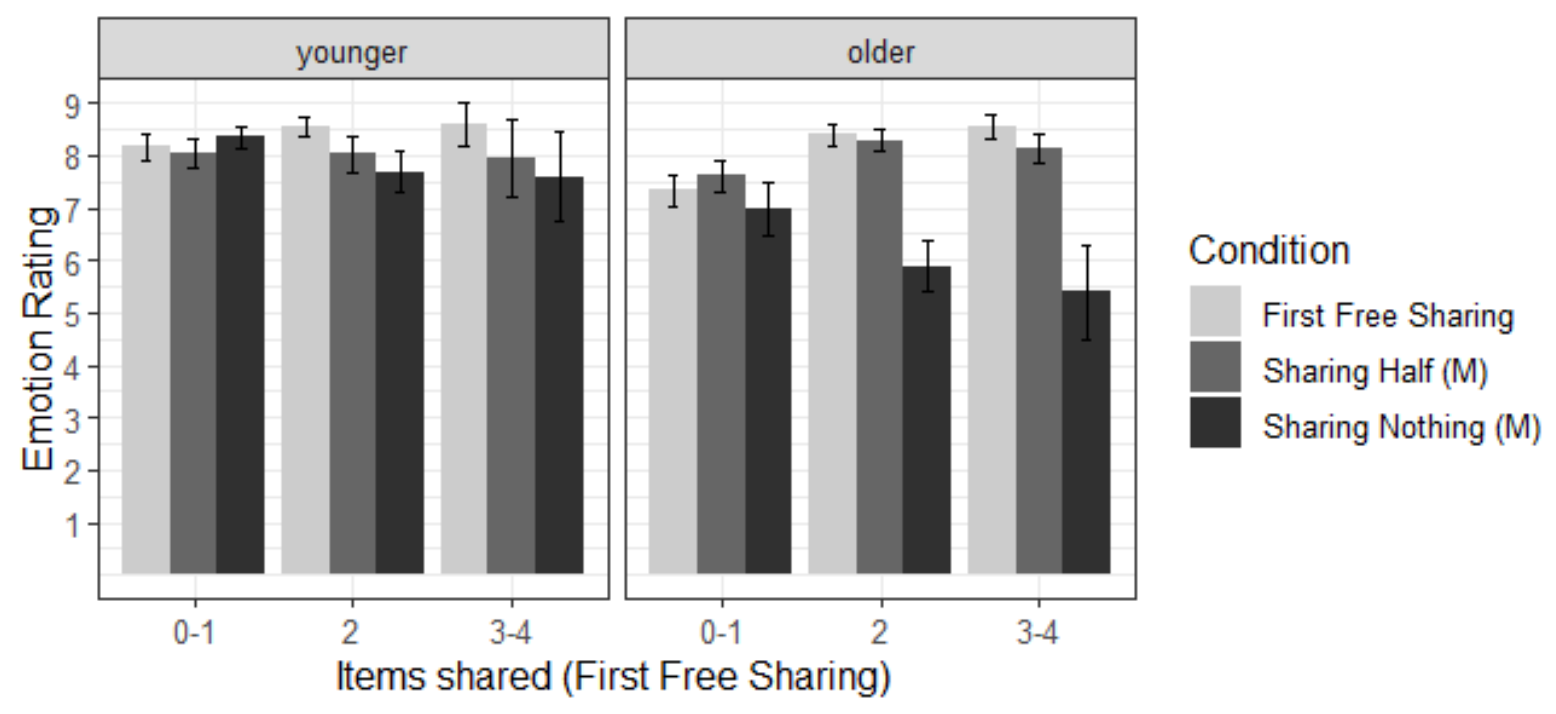

Figure 2. Emotion ratings after First Free Sharing and mean emotion ratings after Sharing Half and Sharing Nothing depending on the amount children shared in the First Free Sharing trial and divided by Age Group. Error bars represent standard errors of the means.

\section{Discussion}

Experiment 1 aimed at investigating the relation between the moral self-concept and prosocial behavior in middle childhood, in particular the role of affective consequences of sharing. The results provide evidence that middle childhood is an important phase for the development of 
emotions regarding prosocial behavior. We found that older children differentiated emotionally more between sharing and not-sharing than younger children. Moreover, this affective benefit of sharing for older children explained the general tendency of older children to share more.

Interestingly, the results revealed no relation between the explicit or implicit moral selfconcept and prosocial behavior. The missing link between the explicit moral self-concept and prosocial behavior is surprising giving previous literature (e.g., Kochanska et al., 2010). This point will be discussed in greater detail in the general discussion. The missing link between the implicit moral self-concept and prosocial behavior suggests that children at that age have not yet formed an implicit self-concept that is meaningfully related to prosocial behavior. The conclusion that chronically accessible moral schemas might not yet be consolidated also explains the missing link with emotions about prosocial behavior. Research on other domains revealed early relations between implicit identity-concept and attitudes, e.g., regarding genderidentity and gender preferences (Cvencek, Greenwald, \& Meltzoff, 2016). However, while gender is a very dominant feature, children might be less aware of the extent to which they behave prosocially. This awareness might increase with age based on experiences with own behavior and feedback of others (Bem, 1972; Brummelman \& Thomaes, 2017). Thus, implicit representations of oneself as a child who acts prosocially might need more time to consolidate.

While the first experiment found no interrelation between consequential emotions and the moral self-concept, it left open the question whether anticipated emotions play a role in this context. Indeed, current theories on human action control suggest that the anticipation of emotional consequences plays an important role in action selection (e.g., Eder et al., 2015; Ridderinkhof, 2017). This was investigated in the second experiment. In this experiment, we exclusively focused on the explicit self-concept. This decision was based on our expectation that the implicit moral self-concept relates to consequential rather than anticipated emotions, 
INTERPLAY OF MORAL SELF, PROSOCIAL BEHAVIOR, AND EMOTIONS

since consequential emotions are less cognitively controlled. Since we did not find the expected relations in Experiment 1, we decided to drop the implicit measure in Experiment 2.

\section{Experiment 2}

\section{Method}

\section{Participants}

The final sample included 83 children. The sample comprised a group of preschool children (n $=40, M=6 ; 1$ (years;months), $S D=3.06$ months, range: 5;9-6;10; 15 female) and a group of school-aged children ( $\mathrm{n}=43, M=9 ; 1, S D=6.62$ months, range: $8 ; 3-9 ; 10 ; 21$ female). Considerations about sample size were the same as for Experiment 1 . We excluded one additional 8-year-old child due to missing data. All participants were typically developing children living in the surroundings of a large European city. Child's caregiver provided informed written consent for participation. The university's ethics committee had the experiment approved. Children received a present for participation.

\section{Procedure}

The procedure and order of tasks was the same as in Experiment 1, except that we omitted the Implicit Association Test and we switched the order of Free Sharing and Sharing Half/Nothing trials, with Free Sharing trials presented last (see below). The whole procedure lasted around 20 minutes.

\section{Measures}

Sharing task. The sharing task closely followed the one from Experiment 1 , with the difference that Imagined Sharing and Not-Sharing trials replaced the actual Sharing and Not-Sharing trials. This resulted in the following three conditions: Imagined Sharing (sharing half), Imagined NotSharing (sharing nothing), Free Sharing. Free Sharing trials were identical as in Experiment 1. In the Imagined Sharing and Not-Sharing trials, the experimenter allocated four items in front 
INTERPLAY OF MORAL SELF, PROSOCIAL BEHAVIOR, AND EMOTIONS

of the child and asked: "Imagine, you would have shared X items and kept $\mathrm{Y}$ items for yourself. How would you feel about that?" The experimenter illustrated the distribution by placing the items accordingly next to the envelope/box. After each trial, the experimenter retrieved all items. Imagined Sharing and Imagined Not-Sharing trials were presented first (in randomized order), Free Sharing trials were presented last. In this way, we aimed to assess emotions that were actually anticipated and not biased by an emotion that just followed a sharing behavior.

Emotion rating, explicit moral self-concept, and control variables. The procedure, scales, and analysis plans were the same as in Experiment 1.

\section{Results}

In the free sharing trials, children shared on average 2.02 items $(S D=0.68)$. On average, younger children shared less items $(M=1.66, S D=0.66)$ than older children $(M=2.35, S D=$ $0.51), t(81)=-5.32, p<.001, d=1.17$. One-sample t-tests revealed that younger children shared significantly less than half, $t(39)=-3.21, p=.003, d=0.51$, while older children shared more than half, $t(42)=4.52, p<.001, d=0.69$. The explicit moral self-concept was comparable in younger $(M=4.03, S D=0.91)$ and older children $(M=4.33, S D=0.53)$, $t(61.5)=-1.80, p=.077, d=0.40$. Figure 3 presents descriptive statistics of the emotion ratings. The emotion difference between imagined sharing and not-sharing was considerably greater in older $(M=5.28, S D=1.99)$ than younger children $(M=0.59, S D=3.01), t(66.8)=$ $8.32, p<.001, d=1.85$. While anticipated emotions about sharing and not-sharing differed in older children, $t(42)=17.44, p<.001, d=3.71$, they did not differ in younger children, $t(39)$ $=1.23, p=.225, d=0.28$. 
INTERPLAY OF MORAL SELF, PROSOCIAL BEHAVIOR, AND EMOTIONS

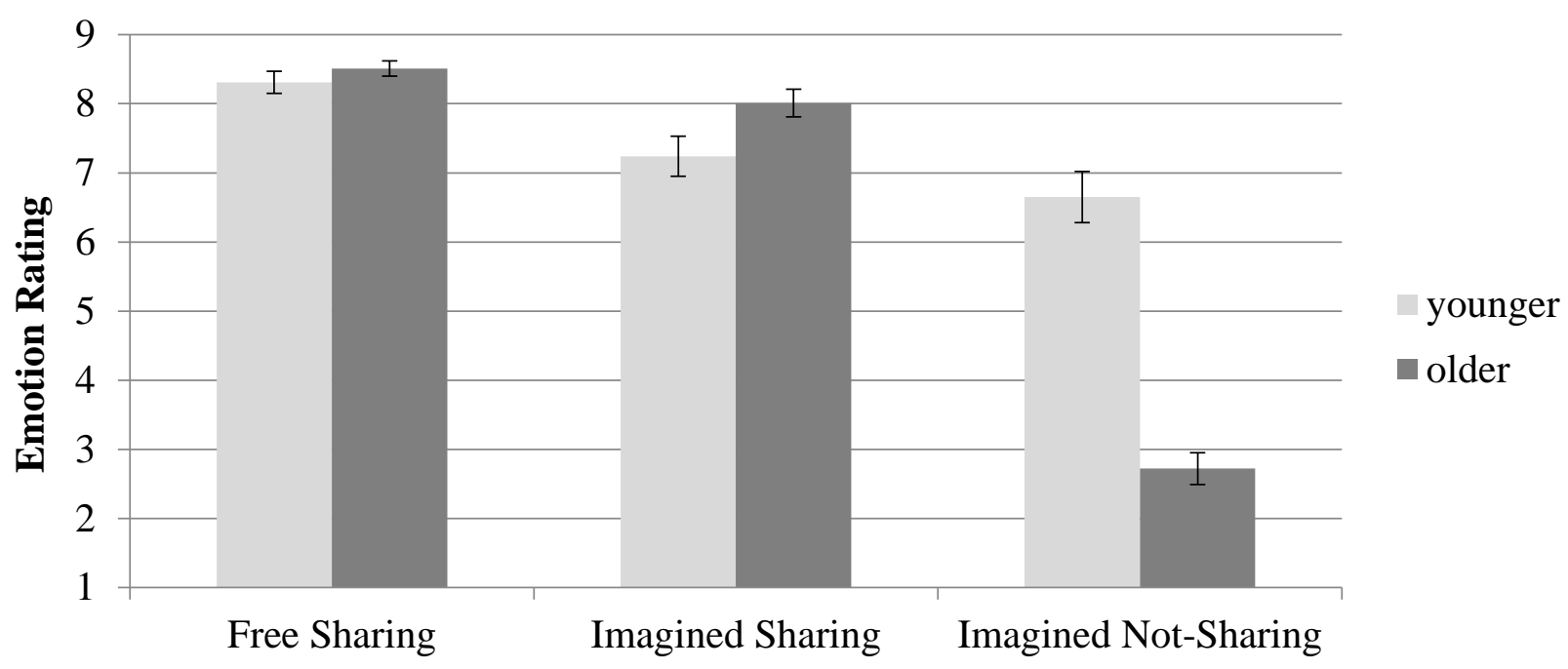

Figure 3. Mean emotion ratings after Free Sharing, Imagined Sharing, and Imagined Not-

Sharing trials divided by Age Group. Error bars represent standard errors of the means.

Table 3 depicts a full correlation matrix using Pearson correlations. We computed hierarchical linear regressions following the procedure from Experiment 1. Table 4 presents the results.

Regarding the relation between the moral self-concept and behavior, the model revealed only a significant effect of age group. That means, older children tended to share more than younger children. The same pattern of results emerged when predicting the emotion differentiation. Only age group significantly predicted the anticipated emotion differentiation, meaning older children differentiated more between Imagined Sharing and Not-Sharing.

When considering emotion differentiation as a predictor of sharing behavior, the regression analyses revealed a strong positive effect of emotion differentiation on sharing behavior. That means, the better children anticipated to feel after sharing compared to notsharing, the more they actually shared afterwards. Age differences did not account for this effect but explained additional variance in sharing behavior. The effects of age group and emotion differentiation did not interact.

Since we did not find the relevant predictions of sharing behavior and anticipated emotion differentiation from the moral self-concept while controlling for age differences, we 
INTERPLAY OF MORAL SELF, PROSOCIAL BEHAVIOR, AND EMOTIONS

omitted the planned mediation analysis. Instead, given the current pattern of results, we computed an alternative exploratory meditation analyses focusing specifically on emotions that children anticipated when omitting prosocial behavior. We decided for this analysis based on the finding that the relation between the moral self-concept and emotion differentiation primarily resulted from the emotions regarding not-sharing (see Table 3). In addition, also previous studies reported a stronger role for negative than positive emotions (Ongley \& Malti, 2014; Paulus \& Moore, 2017). Figure 4 presents the results of the mediation analysis. While controlling for the influence of social desirability and age, the moral self-concept predicted emotions regard not-sharing, which in turn predicted prosocial behavior. The indirect effect, computed using percentile bootstrapping with 10000 samples, was marginally significant, 95\% CI $[0.007,0.148]$, suggesting that the stronger children's moral self-concept, the worse they expected to feel when they would not share, thus the more they shared.

Additionally, we computed a mediation analysis to investigate the underlying mechanism of the age effect. We tested whether anticipated emotion differentiation mediate the age effect on sharing behavior, since correlational analyses revealed a relation between age group and emotion differentiation, between emotion differentiation and sharing behavior, as well as between age group and sharing behavior. Percentile bootstrapping with 10000 samples revealed a significant indirect effect, 95\% CI [0.05, 0.48], meaning that older children expected to feel better after sharing compared to not-sharing, and thus shared subsequently more. Hence, the expected affective benefits of sharing mediated a significant proportion of the age effect on sharing behavior. Nevertheless, age was related to sharing behavior beyond the effect of emotion differentiation.

Table 3

Full correlation matrix of all variables in Experiment 2. 


\begin{tabular}{ccccccc}
\hline & $\mathbf{1}$ & $\mathbf{2}$ & $\mathbf{3}$ & $\mathbf{4}$ & $\mathbf{5}$ & $\mathbf{6}$ \\
\hline $\mathbf{2}$ & $0.21^{+}$ & - & & & & \\
$\mathbf{3}$ & $0.30^{* *}$ & $0.49 * * *$ & - & & & \\
$\mathbf{4}$ & 0.11 & 0.09 & $0.61^{* * *}$ & - & & \\
$\mathbf{5}$ & $-0.31^{* *}$ & $-0.56^{* * *}$ & $-0.89^{* * *}$ & -0.18 & - & \\
$\mathbf{6}$ & $0.26^{*}$ & $-0.26^{*}$ & $-0.25^{*}$ & 0.01 & $0.32 * *$ & - \\
$\mathbf{7}$ & $0.20^{+}$ & $0.51 * * *$ & $0.68^{* * *}$ & $0.24 *$ & $-0.71 * * *$ & $-0.48^{* * *}$ \\
\hline
\end{tabular}

Note. (1) Explicit moral self-concept: Sharing; (2) Free sharing behavior; (3) Mean emotion differentiation; (4) Mean anticipated emotion regarding sharing; (5) Mean anticipated emotion regarding not-sharing; (6) Social desirable response tendency; (7) Age Group [0: younger; 1: older]. $* * * \mathrm{p}<.001 ; * * \mathrm{p}<.01 ; * \mathrm{p}<.05 ;{ }^{+} \mathrm{p}<.1$.

Table 4

Hierarchical linear regressions on free sharing behavior and anticipated emotion differentiation. For the models, $R^{2}$ and p-values are reported; for the individual predictors, standardized beta-values and p-values are reported.

\begin{tabular}{|c|c|c|c|c|c|c|c|c|}
\hline & \multicolumn{4}{|c|}{ Sharing Behavior } & \multicolumn{4}{|c|}{ Anticip. Emotion Diff. } \\
\hline & \multicolumn{2}{|c|}{ Step 1} & \multicolumn{2}{|c|}{ Step 2} & \multicolumn{2}{|c|}{ Step 1} & \multicolumn{2}{|c|}{ Step 2} \\
\hline & $\beta$ & $p$ & $\beta$ & $p$ & $\beta$ & $p$ & $\beta$ & $p$ \\
\hline Social Desirability & -.09 & .480 & & & .03 & .801 & & \\
\hline Explicit Self-Con. & .14 & .183 & & & .16 & .074 & & \\
\hline Age Group & .44 & .000 & & & .66 & .000 & & \\
\hline Expl. SC x Age Group & & & -1.08 & .099 & & & -.88 & .108 \\
\hline $\mathrm{R}^{2}, \mathrm{p}$ & 0.28 & .000 & .30 & .000 & 0.50 & .000 & .51 & .000 \\
\hline Anticip. Emotion Diff. & .27 & .037 & & & & & & \\
\hline Age Group & .32 & .014 & & & & & & \\
\hline Ant. Em. x Age Group & & & -.20 & .401 & & & & \\
\hline $\mathrm{R}^{2}, \mathrm{p}$ & 0.30 & .000 & .30 & .000 & & & & \\
\hline
\end{tabular}




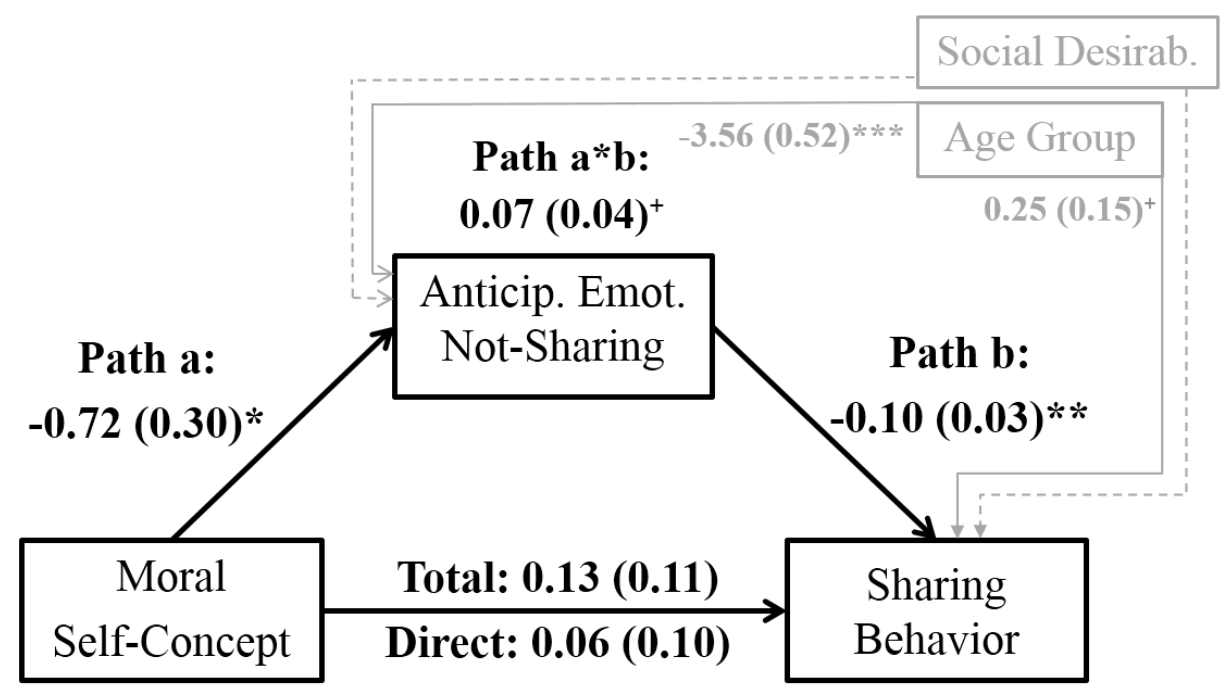

Figure 4. Indirect effect of the moral self-concept on sharing behavior through anticipated emotions regarding not-sharing with parameter estimates (standard errors). Variables in grey depict control variables. Dashed arrows represent non-significant relations. $* * * p<.001 ; * * p$ $<.01 ; * \mathrm{p}<.05 ;{ }^{+} \mathrm{p}<.1$.

\section{Discussion}

Experiment 2 aimed at investigating the role of anticipated emotions regarding prosocial behavior for the relation between the moral self-concept and behavior. In particular, we examined the relation between anticipated emotions and prosocial behavior, between the moral self-concept and prosocial behavior, and whether anticipated emotions mediate the latter relation. As in Experiment 1, the findings revealed that older children differentiated emotionally more between sharing and not-sharing compared to younger children. Moreover, younger children shared less items than older children did. Faced with this typical age effect, one remaining question is: Which cognitive or affective processes that develop with age lead to an increase in sharing behavior? The current experiment suggests one, namely anticipated emotions regarding (not-)sharing. In addition, exploratory analyses suggest that anticipated emotions regarding not-sharing in particular tend to mediate the relation between the moral self-concept and behavior. Nevertheless, age explained sharing behavior beyond the effect of anticipated emotions, suggesting that other mechanisms are guiding sharing behavior across 
INTERPLAY OF MORAL SELF, PROSOCIAL BEHAVIOR, AND EMOTIONS

middle childhood as well. We will follow up on this point and the other findings in the general discussion.

\section{Analyses across Experiments}

In order to address the relation between the moral self-concept and prosocial behavior with a larger sample size, and in order to investigate the effect of anticipating emotions compared to consequential emotions on prosocial behavior, we computed $t$-tests and regressions across both experiments $(N=169)$.

An independent sample t-test of children's sharing behavior between the two experiments revealed that children shared more items in Experiment $2(M=2.02, S D=0.68)$ than in Experiment $1(M=1.72, S D=0.86), t(161)=2.55, p=.012, d=0.39$. Experiment 1 and 2 differed next to the different types of investigated emotions mainly in their task order (anticipated/consequential emotions regarding sharing assessed before/after free sharing). This means, children who first thought about how they would feel when they (won't) share subsequently shared more compared to children who did not think about the emotional consequences of possible actions beforehand.

The emotion differentiation between sharing and not-sharing was smaller for consequential emotions in Experiment $1(M=1.04, S D=2.21)$, compared to anticipated emotions in Experiment $2(M=3.02, S D=3.45), t(138.9)=-4.42, p<.001, d=0.69$. This difference was mostly driven by the more negative emotions regarding anticipated not-sharing in Experiment 2, $(M=4.61, S D=2.77)$ compared to the emotions following not-sharing in Experiment $1(M=7.01, S D=2.15), t(154.6)=6.27, p<.001, d=0.97$. The moral self-concept was comparable in the two experiments, $t(167)=1.53, p=.128, d=0.24$.

Table 5 presents the results of hierarchical linear regressions. In Step 1, we entered social desirability, experiment (as a factor for the different emotion manipulation in Experiment 
1 and 2), the moral self-concept, and age group. In Step 2, we entered relevant two-way interactions and in Step 3 the three-way interaction. The experimental manipulation, the moral self-concept, and age group remained significant predictors of sharing behavior, but they did not interact. Thus, across both experiments, the moral self-concept was related to prosocial behavior beyond the effects of experimental manipulation and age.

\section{Table 5}

Hierarchical linear regressions on free sharing behavior across experiments. For the models, $R^{2}$ and p-values are reported; for the individual predictors, standardized beta-values and pvalues are reported.

\begin{tabular}{|c|c|c|c|c|c|c|}
\hline & \multicolumn{6}{|c|}{ Sharing Behavior } \\
\hline & \multicolumn{2}{|c|}{ Step 1} & \multicolumn{2}{|c|}{ Step 2} & \multicolumn{2}{|c|}{ Step 3} \\
\hline & $\beta$ & $p$ & $\beta$ & $p$ & $\beta$ & $p$ \\
\hline Social Desirability & -.04 & .594 & & & & \\
\hline Experiment & .21 & .004 & & & & \\
\hline Explicit Self-Concept & .18 & .022 & & & & \\
\hline Age Group & .30 & .000 & & & & \\
\hline Experiment x Expl. SC & & & -.35 & .464 & & \\
\hline Experiment x Age Group & & & .14 & .290 & & \\
\hline Expl. SC x Age Group & & & -.13 & .788 & & \\
\hline Exp. x Expl. SC x Age Group & & & & & -1.33 & .120 \\
\hline $\mathrm{R}^{2}, \mathrm{p}$ & 0.16 & .000 & .17 & .000 & .19 & .000 \\
\hline$\triangle \mathrm{R}^{2}, \mathrm{p}$ & & & .01 & .618 & .01 & .120 \\
\hline
\end{tabular}

\section{General Discussion}

The current study assessed the interrelation and joint impact of the moral self-concept and emotions on children's prosocial behavior. This allowed us to investigate the nature of the relation between the moral self-concept and prosocial behavior. Overall, the moral self-concept was positively related to prosocial behavior in middle childhood. Likewise, both consequential 
and anticipated emotions regarding sharing predicted prosocial behavior positively. From a developmental view most important, both types of emotions accounted for age differences in sharing behavior. Exploratory analyses suggest that the avoidance of negative emotions when not behaving prosocially mediates the relation between the moral self-concept and behavior. Moreover, asking children first to anticipate the affective consequences of (not-)sharing increased subsequent sharing behavior. The findings speak to several current theoretical debates and suggest a number of conclusions.

One key developmental question concerns why selfish behavior decreases with age (e.g., Fehr, Bernhard, \& Rockenbach, 2008; Kogut, 2012; Smith et al., 2013). The current study highlights the role of emotions regarding prosocial behavior for this development. Both consequential and anticipated emotions regarding sharing mediated age effects on behavior. That is, the better children anticipated to feel or actually felt after sharing than not-sharing, the more items they shared themselves. This finding supports the notion that emotions guide behavior (Barrett, 1998; Tangney, Stuewig, \& Mashek, 2007) and corroborates current theoretical proposals that the anticipation of emotional consequences affects future behavior (Eder et al., 2015; Ridderinkhof, 2017). Even though anticipated and consequential emotions tend to differ (Gautam et al., 2017; Wilson \& Gilbert, 2005), the functional outcome, namely their effect on sharing behavior, appears to be similar. Interestingly, the relation between emotions and sharing behavior relied mostly on negative emotions that result from not sharing. This finding extends previous work regarding anticipated emotions (Gummerum, Hanoch, Keller, Parsons, \& Hummel, 2010; Ongley \& Malti, 2014; Paulus \& Moore, 2017) by highlighting one developmental factor that could explain developmental differences in children's sharing behavior.

Emotions regarding prosocial behavior seem to undergo profound changes in middle childhood. Older children both anticipated to feel better and actually felt better after sharing 
INTERPLAY OF MORAL SELF, PROSOCIAL BEHAVIOR, AND EMOTIONS

compared to not sharing, while younger children did not differentiate. These findings parallel the literature on emotion attributions (e.g., Keller, Lourenço, Malti, \& Saalbach, 2003; NunnerWinkler \& Sodian, 1988). One possible explanation for this emotion pattern is that children first know about moral rules in an informational sense, without experiencing it as a personal obligation to follow them. Thus, they might not feel worse after acting against the rule (NunnerWinkler, 2007). Our finding corresponds to work by Smith and colleagues (2013) who reported that younger children knew that sharing equally would be required, but actually shared less than half. In the course of middle childhood, cognitive and personal motivational aspects seem to become integrated, leading to an obligatory understanding of moral norms and negative emotions following norm transgressions (Nunner-Winkler, 2007). Our finding that emotions were related to actual sharing behavior supports a motivational interpretation of the emotion patterns.

Importantly, children's sharing behavior differed between the two experiments, such that children who first reflected on their future affective state shared more. This effect might result from the emotion differentiation that differs between consequential and anticipated emotions: When anticipating the emotional consequences, children differentiated more between sharing and not-sharing compared to when they reported their emotions after having shared or notshared. This difference was driven by the not-sharing trials, which elicited more negative anticipated rather than experienced emotions. While our results add to the debate on the role of reflection for children's development (e.g., Allen \& Bickhard, 2018), the pattern might be explained by two, potentially overlapping, mechanisms: First, research on affective forecasting reports that people tend to overestimate the intensity of future emotional reactions (Wilson \& Gilbert, 2005). For example, Gautam, Bulley, von Hippel, \& Suddendorf (2017) reported the intensity bias specifically regarding negative emotions in preschool children. Thus, children in the current study might have overestimated how bad they would feel when they would not 
share. Second, children who were requested to keep all items might have adapted their emotional state (more positive) to reduce cognitive dissonance between their behavior and attitude regarding the behavior (Festinger, 1957). However, when interpreting findings across experiments, we have to keep in mind that the participant assignment to conditions (consequential, anticipated emotions) was not completely random, as the conditions were set up as two different experiments. Nevertheless, the finding that reflecting on own affective consequences seems to increase sharing behavior is an interesting starting point for possible interventions on children's prosocial behavior.

Central to our research question, the results contribute to literature that proposes the moral self-concept as a predictor of moral behavior (e.g., Blasi, 1983; Hardy \& Carlo, 2011). Analyses across both experiments with a larger sample size and thus more statistical power revealed a relation beyond the effect of age and social desirability (which was not present in the single experiments). This finding contributes to previous research on the development of the moral self-concept (for overview see Krettenauer, 2013; Thompson, 2012). It suggests that the moral self-concept is meaningfully, but weakly related to prosocial behavior in middle childhood. Notably, previous work demonstrated relations between the moral self-concept and behavior in early childhood (Kochanska, 2002; Kochanska et al., 2010; Sengsavang \& Krettenauer, 2015). However, these studies did not focus on active prosocial behavior but on parental report or compliance. Our study adds to this literature by demonstrating the behavioral relevance of the moral self-concept in childhood. Post-hoc analyses indicate that the missing effects in the individual experiments stem from a lack of power. A sensitivity analysis revealed that with the given sample sizes in the individual experiments, an alpha level of 0.05 and a power of 0.80 , we were able to detect effect sizes of $f^{2}=0.09$ in the multiple regressions. However, the regression analysis across experiments revealed an effect size of the moral self-concept of $f^{2}=$ 0.03. Given the sample size across experiments, the analysis across experiments had a power 
INTERPLAY OF MORAL SELF, PROSOCIAL BEHAVIOR, AND EMOTIONS

of 0.65 to detect an effect of this size. Overall, the findings thus indicate a relation between the moral self-concept and prosocial behavior in childhood albeit smaller than initially expected.

Regression analyses revealed that the moral self-concept did not predict experienced (Experiment 1) but anticipated emotional consequences (Experiment 2). Emotions following prosocial behavior thus seem to be independent, while anticipated emotions seem to be related to the moral self-concept in middle childhood. This finding extends previous research by supporting a relation between the moral self-concept and emotions regarding prosocial behavior earlier than previously concluded, although it should be noted that the effect became marginal when additionally controlling for age. Recent studies repeatedly found a link between moral emotions and the moral self-concept in adolescence and adults (Johnston \& Krettenauer, 2011; Lefebvre \& Krettenauer, 2019). Using hypothetical scenarios, Krettenauer et al. (2013) reported a significant link in 12-year-olds, but not 8-year-olds. Our finding suggests the relation between anticipated emotions and self-concept in real-life scenarios to be present already in middle childhood.

The current findings are highly informative for theories on the link between moral emotions and moral self-concept development. From a functionalist approach, emotions serve as signals to the environment and to oneself, signaling the significance of an event and guiding subsequent actions (Barrett, 1998; Vaish, 2018). In the process of building a self-concept, children may rely on their emotional experience to learn about their values and to decide for future actions. Alternatively, emotions could be the consequence of acting consistent or inconsistent with one's values, as already reflected in the moral self-concept (Blasi, 1999; Sheldon \& Elliot, 1999). Our results suggest that the formation of the moral self-concept does not build on emotional experiences, since the moral self-concept and actual emotional consequences of prosocial behavior were independent in middle childhood. Rather, the moral self-concept was related to anticipated emotions. Anticipating emotions about future behavior 
is an active process, which results in a cognitive representation of an emotion (Krettenauer, 2012). When constructing this anticipated emotion, children might rely on various information: They might integrate their impression about how one should behave, together with their impression about how important it is for them to act in a certain way, that is, their self-concept. Through this constructive process, the moral self-concept might influence anticipated emotions, and consequently prosocial behavior. By revealing a relation between the moral self-concept and anticipated emotions, our findings thus support the notion that anticipated emotions in middle childhood not only reflect expected outcomes, but inconsistencies with personal values (Krettenauer, 2012). Thus, our results are suggestive for the idea that the moral self-concept promotes sharing behavior through the avoidance of anticipated negative emotions.

Based on self-determination theory, integrating morality into one's sense of self should result in internal moral motivation, which would result in prosocial behavior being satisfactory. However, the finding that mostly negative emotions linked the moral self-concept and behavior speaks for a relatively more external ("introjected") motivation, building on the pressure to avoid negative feelings (Ryan \& Deci, 2000). This finding supports the developmental model by Krettenauer (2013), who suggests that only by late childhood (individually variable between children), the moral self-concept reflects the integration of moral behavior into the self, allowing for internal motivation. In addition, the result is in line with previous developmental research that suggests external motives as dominant for refraining from antisocial behavior during childhood (Sengsavang, Willemsen, \& Krettenauer, 2015). The moral self-concept during childhood thus seems to reflect a child's view of him-/herself with regard to prosocial behavior that might receive its motivational power through striving for approval or a positive self-esteem (even though the motivation seems to be context-dependent, see Sengsavang et al., 2015). A more advanced self-concept with age, built on more abstract terms and self-evaluative stances, might allow for an integration of morality into the self and thus for a motivation 
INTERPLAY OF MORAL SELF, PROSOCIAL BEHAVIOR, AND EMOTIONS

emanating from the self. In line with that notion, internal moral motivation seems to increase across childhood (Sengsavang et al., 2015) and adulthood (Krettenauer \& Victor, 2017).

As discussed above, particularly anticipated emotions seem to be related to the early moral self-concept. Besides that, findings for anticipated emotions resembled findings for consequential emotions. The developmental pattern of both types of emotions was similar, such that younger children on average emotionally differentiated neither between actual nor anticipated sharing and not-sharing, while older children did so for both. Children thus seem to start considering sharing as emotionally relevant in their cognitively constructed anticipated emotions and in their actually experienced emotions to a similar time point. Future longitudinal studies would be valuable to corroborate this conclusion.

While the current study is informative for theories on prosocial behavior, it also has limitations. The samples were drawn from a Western, individualistic population. Previous research revealed that in particular sharing behavior differs between cultures from middle childhood on (Callaghan \& Corbit, 2018). Additionally, in Eastern compared to Western cultures, the self is construed more in relation to its social context and a consistent self-concept seems to be less valued (Markus \& Kitayama, 1991; Suh, 2002). The self-concept might thus be less critical for behavior in collectivistic compared to individualistic cultures. Further research is necessary to examine the generalizability of our results to other cultures. In addition, we restricted our study to one domain of prosocial behavior, namely sharing. Future investigations regarding helping or comforting behavior would inform about the generalizability of the present results and contribute to literature suggesting different prosocial domains (Dunfield, 2014; Paulus, 2018). Furthermore, the current study leaves the nature of the emotions that predict prosocial behavior open. The relation between emotions and the moral self-concept speaks for a self-relevant aspect contained in the emotions, thus, guilt avoidance might be one mechanism underlying the relation between negative emotions and behavior 
(Vaish, 2018). Likewise, the negative emotions might stem, for example, from an awareness of a sharing norm or from an awareness of the recipient's feelings. Future research should thus investigate and specify the emotions that predict behavior in detail. In addition, age was positively related to sharing behavior beyond the effect of emotions (Experiment 2). Further mechanisms that underlie these age effects should be addressed by future research. Predictors of the individual differences in emotions remain a topic for future research as well. Addressing the role of parent-child interaction, for example parents' talk about emotions with the child, might be an interesting line of research. Moreover, the explicit self-concept measure focused on behavioral preferences, as in previous research with children (e.g., Kochanska, 2002; Sengsavang \& Krettenauer, 2015). However, since children start to integrate their actions into a higher-order representation in middle childhood, the development of a more generalized moral self-concept measure would be helpful for future research. Additionally, prosocial behavior in older children might manifest itself in different situations than in younger children. Nevertheless, assessing the moral self-concept the same way in all children allowed us to draw conclusions about the development across both ages and revealed meaningful associations.

To conclude, the current study informs theoretical proposals on the importance of cognitive and affective mechanisms, namely the moral self-concept and emotions, for prosocial behavior. It extends previous literature by showing that the moral self-concept is related to prosocial behavior, in particular through the avoidance of negative emotions. Additionally, increasing emotional differentiation regarding sharing and not-sharing in middle childhood accounts for age differences in sharing behavior. Finally, the study suggests that asking children to reflect on the affective consequences of (the omission of) prosocial behavior enhanced children's prosocial behavior, thus providing a basis for future interventions. 
INTERPLAY OF MORAL SELF, PROSOCIAL BEHAVIOR, AND EMOTIONS

\section{References}

Aknin, L. B., Hamlin, J. K., \& Dunn, E. W. (2012). Giving leads to happiness in young children. PLoS ONE, 7(6), e39211. https://doi.org/10.1371/journal.pone.0039211

Aknin, L. B., Van de Vondervoort, J. W., \& Hamlin, J. K. (2018). Positive feelings reward and promote prosocial behavior. Current Opinion in Psychology, 20, 55-59. https://doi.org/10.1016/j.copsyc.2017.08.017

Allen, J. W. P., \& Bickhard, M. H. (2018). Stage fright: Internal reflection as a domain general enabling constraint on the emergence of explicit thought. Cognitive Development, 45, 77-91. https://doi.org/10.1016/j.cogdev.2017.12.005

Aquino, K., \& Reed, A. I. (2002). The self-importance of moral identity. Journal of Personality and Social Psychology, 83(6), 1423-1440. https://doi.org/10.1037//00223514.83.6.1423

Barrett, K. C. (1998). A functionalist perspective to the development of emotions. In M. F. Mascolo \& S. Griffin (Eds.), What Develops in Emotional Development? (pp. 109-133). Retrieved from http://www.eric.ed.gov/ERICWebPortal/recordDetail?accno=ED422112

Bem, D. J. (1972). Self-Perception Theory. Advances in Experimental Social Psychology, 6, $1-62$.

Bierhoff, H.-W. (2002). Prosocial Behaviour. London: Psychology Press.

Blasi, A. (1983). Moral cognition and moral action: A theoretical perspective. Developmental Review, 3(2), 178-210. https://doi.org/10.1016/0273-2297(83)90029-1

Blasi, A. (1999). Emotions and moral motivation. Journal for the Theory of Social Behaviour, 29(1), 1-19. https://doi.org/10.1111/1468-5914.00088

Brownell, C. A. (2013). Early development of prosocial behavior: Current perspectives. Infancy, 18(1), 1-9. https://doi.org/10.1111/infa.12004

Brummelman, E., \& Thomaes, S. (2017). How children construct views of themselves: A 
INTERPLAY OF MORAL SELF, PROSOCIAL BEHAVIOR, AND EMOTIONS

social-developmental perspective. Child Development, 88(6), 1763-1773. https://doi.org/10.1111/cdev.12961

Callaghan, T., \& Corbit, J. (2018). Early prosocial development across cultures. Current Opinion in Psychology, 20, 102-106. https://doi.org/10.1016/j.copsyc.2017.07.039

Caprara, G. V., Barbaranelli, C., Pastorelli, C., Bandura, A., \& Zimbardo, P. G. (2000). Prosocial foundations of children's academic achievment. Psychological Science, 11(4), 302-306. https://doi.org/10.1177/1469787405057750

Carpendale, J. I. M., Hammond, S. I., \& Atwood, S. (2013). A relational developmental systems approach to moral development. Advances in Child Development and Behavior, 45, 125-153. https://doi.org/10.1016/B978-0-12-397946-9.00006-3

Cvencek, D., Greenwald, A. G., \& Meltzoff, A. N. (2011). Measuring implicit attitudes of 4year-olds: The Preschool Implicit Association Test. Journal of Experimental Child Psychology, 109(2), 187-200. https://doi.org/10.1016/j.jecp.2010.11.002

Cvencek, D., Greenwald, A. G., \& Meltzoff, A. N. (2016). Implicit measures for preschool children confirm self-esteem's role in maintaining a balanced identity. Journal of Experimental Social Psychology, 62, 50-57. https://doi.org/10.1016/j.jesp.2015.09.015

De Wit, S., \& Dickinson, A. (2009). Associative theories of goal-directed behaviour: A case for animal-human translational models. Psychological Research, 73(4), 463-476. https://doi.org/10.1007/s00426-009-0230-6

Denham, S. (1986). Social cognition, prosocial behavior, and emotion in preschoolers: Contextual validation. Child DevelopmentChild Development, 57(1), 194-201.

Dunfield, K. A. (2014). A construct divided: Prosocial behavior as helping, sharing, and comforting subtypes. Frontiers in Psychology, 5, 1-13. https://doi.org/10.3389/fpsyg.2014.00958

Dunfield, K., Kuhlmeier, V. A., O’Connell, L., \& Kelley, E. (2011). Examining the Diversity 
INTERPLAY OF MORAL SELF, PROSOCIAL BEHAVIOR, AND EMOTIONS

of Prosocial Behavior: Helping, Sharing, and Comforting in Infancy. Infancy, 16(3), 227-247. https://doi.org/10.1111/j.1532-7078.2010.00041.x

Dunn, E. W., Aknin, L. B., \& Norton, M. I. (2008). Spending money on others promotes happiness. Science, 319(5870), 1687-1688. https://doi.org/10.1126/science.1150952

Eder, A. B., Rothermund, K., De Houwer, J., \& Hommel, B. (2015). Directive and incentive functions of affective action consequences: an ideomotor approach. Psychological Research, 79(4), 630-649. https://doi.org/10.1007/s00426-014-0590-4

Eisenberg, N. (2000). Emotion, regulation, and moral development. Annual Review of Psychology, 51, 665-697. https://doi.org/10.1146/annurev.psych.51.1.665

Elenbaas, L. (2019). Against unfairness: Young children's judgments about merit, equity, and equality. Journal of Experimental Child Psychology, 186, 73-82.

https://doi.org/10.1016/j.jecp.2019.05.009

Erdfelder, E., Faul, F., \& Buchner, A. (1996). GPOWER: A general power analysis program. Behavior Research Methods, Instruments, \& Computers, 28(I), 1-11.

Fehr, E., Bernhard, H., \& Rockenbach, B. (2008). Egalitarianism in young children. Nature, 454(7208), 1079-1083. https://doi.org/10.1038/nature07155

Festinger, L. (1957). A theory of cognitive dissonance. Stanford, CA: Stanford University Press.

Flynn, E., Ehrenreich, S. E., Beron, K. J., \& Underwood, M. K. (2015). Prosocial behavior: Long-term trajectories and psychosocial outcomes. Social Development, 24(3), 462-482. https://doi.org/10.1111/sode.12100

Fritz, M. S., \& MacKinnon, D. P. (2007). Required sample size to detect the mediated effect. Psychological Science, 18(3), 233-239. https://doi.org/10.1111/j.14679280.2007.01882.x

Gautam, S., Bulley, A., von Hippel, W., \& Suddendorf, T. (2017). Affective forecasting bias 
INTERPLAY OF MORAL SELF, PROSOCIAL BEHAVIOR, AND EMOTIONS

in preschool children. Journal of Experimental Child Psychology, 159, 175-184. https://doi.org/10.1016/j.jecp.2017.02.005

Greenwald, A. G., Nosek, B. A., \& Banaji, M. R. (2003). Understanding and using the Implicit Association Test: An improved scoring algorithm. Journal Pers Soc Psychol., 85(2), 197-216. https://doi.org/10.1037/0022-3514.85.2.197

Gummerum, M., Hanoch, Y., Keller, M., Parsons, K., \& Hummel, A. (2010). Preschoolers' allocations in the dictator game: The role of moral emotions. Journal of Economic Psychology, 31(1), 25-34. https://doi.org/10.1016/j.joep.2009.09.002

Hardy, S. A., \& Carlo, G. (2011). Moral identity: What is it, how does it develop, and is it linked to moral action? Child Development Perspectives, 5(3), 212-218. https://doi.org/10.1111/j.1750-8606.2011.00189.x

Hardy, S. A., Walker, L. J., Olsen, J. a, Woodbury, R. D., \& Hickman, J. R. (2014). Moral identity as moral ideal self: links to adolescent outcomes. Developmental Psychology, 50(1), 45-57. https://doi.org/10.1037/a0033598

Harter, S. (2007). The Self. In W. Damon, R. M. Lerner, \& N. Eisenberg (Eds.), Handbook of Child Psychology (6th ed., pp. 505-570). https://doi.org/10.1002/9780470147658.chpsy0309

Hertz, S. G., \& Krettenauer, T. (2016). Does moral identity effectively predict moral behavior?: A meta-analysis. Review of General Psychology Psychology, 20(2), 129-140. https://doi.org/http://dx.doi.org.myaccess.library.utoronto.ca/10.1037/gpr0000062

Johnston, M., \& Krettenauer, T. (2011). Moral self and moral emotion expectancies as predictors of anti- and prosocial behaviour in adolescence: A case for mediation? European Journal of Developmental Psychology, 8(2), 228-243. https://doi.org/10.1080/17405621003619945

Keller, M., Lourenço, O., Malti, T., \& Saalbach, H. (2003). The multifaceted phenomenon of 
INTERPLAY OF MORAL SELF, PROSOCIAL BEHAVIOR, AND EMOTIONS

"happy victimizers": A cross-cultural comparison of moral emotions. British Journal of Developmental Psychology, 21(1), 1-18. https://doi.org/10.1348/026151003321164582

Kingsford, J. M., Hawes, D. J., \& de Rosnay, M. (2018). The moral self and moral identity:

Developmental questions and conceptual challenges. British Journal of Developmental Psychology, 1-15. https://doi.org/10.1111/bjdp.12260

Kochanska, G. (2002). Committed compliance, moral self, and internalization: a mediational model. Developmental Psychology, 38(3), 339-351. https://doi.org/10.1037/00121649.38.3.339

Kochanska, G., Koenig, J. L., Barry, R. A., Kim, S., \& Yoon, J. E. (2010). Children’s conscience during toddler and preschool years, moral self, and a competent, adaptive developmental trajectory. Developmental Psychology, 46(5), 1320-1332. https://doi.org/10.1037/a0020381

Kogut, T. (2012). Knowing what I should, doing what I want: From selfishness to inequity aversion in young children's sharing behavior. Journal of Economic Psychology, 33(1), 226-236. https://doi.org/10.1016/j.joep.2011.10.003

Krettenauer, T. (2012). Linking moral emotion attributions with behavior: Why "(un)happy victimizers" and "(un)happy moralists" act the way they feel. New Directions for Youth Development, 136, 59-74.

Krettenauer, T. (2013). Revisiting the moral self-construct: Developmental perspectives on moral selfhood. In B. W. Sokol, F. M. E. Grouzet, \& U. Müller (Eds.), Self-regulation and autonomy: Social and developmental dimensions of human conduct (pp. 115-140). Cambridge University Press.

Krettenauer, T., Campbell, S., \& Hertz, S. (2013). Moral emotions and the development of the moral self in childhood. European Journal of Developmental Psychology, 10(2), 159173. https://doi.org/10.1080/17405629.2012.762750 
INTERPLAY OF MORAL SELF, PROSOCIAL BEHAVIOR, AND EMOTIONS

Krettenauer, T., \& Victor, R. (2017). Why be moral? Moral identity motivation and age. Developmental Psychology, 53(8), 1589-1596. https://doi.org/10.1037/dev0000353

Lapsley, D. K., \& Hill, P. L. (2008). On dual processing and heuristic approaches to moral cognition. Journal of Moral Education, 37(3), 313-332.

https://doi.org/10.1080/03057240802227486

Lefebvre, J. P., \& Krettenauer, T. (2019). Linking moral identity with moral emotions: A meta-analysis. Review of General Psychology, 23(4), 444-457. https://doi.org/10.1177/1089268019880887

Lemerise, E. A., \& Arsenio, W. F. (2000). An Integrated Model of Emotion Processes and Cognition in Social Information Processing. Child Development, 71(1), 107-118. https://doi.org/10.1080/15567036.2010.540627

Malti, T., \& Krettenauer, T. (2013). The relation of moral emotion attributions to prosocial and antisocial behavior: A meta-analysis. Child Development, 84(2), 397-412. https://doi.org/10.1111/j.1467-8624.2012.01851.x

Markus, H. R., \& Kitayama, S. (1991). Culture and the self: Implications for cognition, emotion, and motivation. Psychological Review, 98(2), 224-253. https://doi.org/10.1037//0033-295x.98.2.224

Marsh, H. W., Ellis, L. a, \& Craven, R. G. (2002). How do preschool children feel about themselves? Unraveling measurement and multidimensional self-concept structure. Developmental Psychology, 38(3), 376-393. https://doi.org/10.1037/0012-1649.38.3.376

McClelland, D. C., Koestner, R., \& Weinberger, J. (1989). How do self-attributed and implicit motives differ? Psychological Review, 96(4), 690-702. https://doi.org/10.1037/0033295X.96.4.690

Nunner-Winkler, G. (2007). Development of moral motivation from childhood to early adulthood. Journal of Moral Education, 36(4), 399-414. 
INTERPLAY OF MORAL SELF, PROSOCIAL BEHAVIOR, AND EMOTIONS

https://doi.org/10.1080/03057240701687970

Nunner-Winkler, G., \& Sodian, B. (1988). Children's understanding of moral emotions. Child Development, 59(5), 1323-1338.

Ongley, S. F., \& Malti, T. (2014). The role of moral emotions in the development of children's sharing behavior. Developmental Psychology, 50(4), 1148-1159. https://doi.org/10.1037/a0035191

Paulus, M. (2014). The emergence of prosocial behavior: Why do infants and toddlers help, comfort, and share? Child Development Perspectives, 8(2), 77-81. https://doi.org/10.1111/cdep.12066

Paulus, M. (2018). The multidimensional nature of early prosocial behavior: a motivational perspective. Current Opinion in Psychology, 20, 111-116. https://doi.org/10.1016/j.copsyc.2017.09.003

Paulus, M., \& Moore, C. (2017). Preschoolers' generosity increases with understanding of the affective benefits of sharing. Developmental Science, 20(3). https://doi.org/10.1111/desc. 12417

Perrott, D. A., Goodenough, B., \& Champion, G. D. (2004). Children's ratings of the intensity and unpleasantness of post-operative pain using facial expression scales. European Journal of Pain, 8(2), 119-127. https://doi.org/10.1016/S1090-3801(03)00087-9

Perugini, M., \& Leone, L. (2009). Implicit self-concept and moral action. Journal of Research in Personality, 43(5), 747-754. https://doi.org/10.1016/j.jrp.2009.03.015

Pletti, C., Decety, J., \& Paulus, M. (2019). Moral identity relates to the neural processing of third-party moral behavior. Social Cognitive and Affective Neuroscience, 14(4), 435445. https://doi.org/10.1093/scan/nsz016

Rakoczy, H., Kaufmann, M., \& Lohse, K. (2016). Young children understand the normative force of standards of equal resource distribution. Journal of Experimental Child 
INTERPLAY OF MORAL SELF, PROSOCIAL BEHAVIOR, AND EMOTIONS

Psychology, 150, 396-403. https://doi.org/10.1016/j.jecp.2016.05.015

Reese, E., Bird, A., \& Tripp, G. (2007). Children's self-esteem and moral self: Links to parent-child conversations regarding emotion. Social Development, 16(3), 460-478. https://doi.org/10.1111/j.1467-9507.2007.00393.x

Ridderinkhof, K. R. (2017). Emotion in action: A predictive processing perspective and theoretical synthesis. Emotion Review, 9(4), 319-325. https://doi.org/10.1177/1754073916661765

Ross, J. (2017). You and me: Investigating the role of self-evaluative emotion in preschool prosociality. Journal of Experimental Child Psychology, 155, 67-83. https://doi.org/10.1016/j.jecp.2016.11.001

Rosseel, Y. (2012). lavaan: An R Package for Structural Equation Modeling. Journal of Statistical Software, 48(2), 1-36. Retrieved from http://www.jstatsoft.org/v48/i02/

Ryan, R. M., \& Deci, E. L. (2000). Intrinsic and extrinsic motivations: Classic definitions and new directions. Contemporary Educational Psychology, 25(1), 54-67. https://doi.org/10.1006/ceps.1999.1020

Sabato, H., \& Kogut, T. (2019). Feel good, do good? Subjective well-being and sharing behavior among children. Journal of Experimental Child Psychology, 177, 335-350. https://doi.org/10.1016/j.jecp.2018.08.009

Scherer, K. R. (1987). Toward a dynamic theory of emotion: The component process model of affective states. Geneva Studies in Emotion and Communication, 1, 1-98. https://doi.org/10.1017/CBO9781107415324.004

Sengsavang, S., \& Krettenauer, T. (2015). Children's moral self-concept : The role of aggression and parent-child relationships. Merrill-Palmer Quarterly, 61(2), 213-235. https://doi.org/10.13110/merrpalmquar1982.61.2.0213

Sengsavang, S., Willemsen, K., \& Krettenauer, T. (2015). Why be moral? Children's explicit 
INTERPLAY OF MORAL SELF, PROSOCIAL BEHAVIOR, AND EMOTIONS

motives for prosocial-moral action. Frontiers in Psychology, 6(MAY), 1-9.

https://doi.org/10.3389/fpsyg.2015.00552

Sheldon, K. M., \& Elliot, A. J. (1999). Goal striving, need satisfaction, and longitudinal wellbeing: The self-concordance model. Journal of Personality and Social Psychology, 76(3), 482-497.

Smith, C. E., Blake, P. R., \& Harris, P. L. (2013). I should but I won't: Why young children endorse norms of fair sharing but do not follow them. PLoS ONE, 8(3). https://doi.org/10.1371/journal.pone.0059510

Suh, E. M. (2002). Culture, identity consistency, and subjective well-being. Journal of Personality and Social Psychology, 83(6), 1378-1391. https://doi.org/10.1037/00223514.83.6.1378

Tangney, J., Stuewig, J., \& Mashek, D. (2007). Moral emotions and moral behaviour. Annual Review of Psychology, 58, 345-372.

https://doi.org/10.1146/annurev.psych.56.091103.070145.Moral

Thompson, R. A. (2012). Whither the preconventional child? Toward a life-span moral development theory. Child Development Perspectives, 6(4), 423-429. https://doi.org/10.1111/j.1750-8606.2012.00245.x

Vaish, A. (2018). The prosocial functions of early social emotions: the case of guilt. Current Opinion in Psychology, 20, 25-29. https://doi.org/10.1016/j.copsyc.2017.08.008

Williams, A., O’Driscoll, K., \& Moore, C. (2014). The influence of empathic concern on prosocial behavior in children. Frontiers in Psychology, 5(425). https://doi.org/10.3389/fpsyg.2014.00425

Wilson, T. D., \& Gilbert, D. T. (2005). Affective forcasting: Knowing what to want. Current Directions in Psychological Science, 14(3), 131-134. https://doi.org/10.1111/j.09637214.2005.00355.x 
INTERPLAY OF MORAL SELF, PROSOCIAL BEHAVIOR, AND EMOTIONS

Wilson, Timothy D., \& Gilbert, D. T. (2005). Affective forecasting. Advances in Experimental Social Psychology, 35, 345-411. Retrieved from http://journals.sagepub.com/doi/10.1111/j.0963-7214.2005.00355.x

Zaki, J., \& Mitchell, J. P. (2013). Intuitive prosociality. Current Directions in Psychological Science, 22(6), 466-470. https://doi.org/10.1177/0963721413492764 
INTERPLAY OF MORAL SELF, PROSOCIAL BEHAVIOR, AND EMOTIONS

\section{Appendix A}

Table A.1

Items of the adapted Children's Moral Self Puppet Scale.

\begin{tabular}{ll} 
Scale & Item \\
D & I like to play ball. \\
M-S & I like to share my pencils. \\
D & I enjoy looking at books. \\
M-C & I like to console a child, even if it was mean to me once. \\
D & I would like to be strong. \\
M-H & I like to help folding the laundry. \\
M-S & I take care that everyone gets the same amount. \\
D & I like it when people read me a story. \\
M-H & I like to help setting the table at home. \\
S & I always wash my hands before dinner. \\
M-C & I stop playing my favorite game to console a crying child. \\
M-S & I like to let other children play with my toys. \\
S & I always say "please" when asking for something. \\
M-H & I like to help doing the dishes. \\
M-C & I console a child, even when it has started the fight itself. \\
S & I am never angry. \\
\hline
\end{tabular}

Note. D: Distractors; S: Social Desirability; M-S: Moral-Sharing Subscale; M-C: Moral-

Consoling Subscale; M-H: Moral-Helping Subscale. 


\section{Appendix B}

\section{Procedure of the Implicit Association Test in Experiment 1}

The adaptations of our child-friendly IAT relied on previous work (cf. Cvencek, Greenwald, \& Meltzoff, 2011). First, we used simplified words for the category labels and items. Second, auditory stimulus words were presented by a female speaker in order to eliminate the need for reading. The auditory stimulus co-occured with a white circle on the screen to keep the participant's focus of attention. Pictures depicted the category reminders in the top corners of the screen, with a happy/sad smiley representing good/bad and a photo of the participant/another child representing self/others. The photo of another gender- and agematched child was taken from the Radboud Faces Database (Langner et al., 2010). Additionally, a yellow and blue colored stripe marked the left and right side of the screen, and the response buttons had the respective color-codes to simplify the association of side and button. The experimenter highlighted the current response assignment before each block. The procedure followed the original IAT by Greenwald, McGhee, and Schwartz (1998) but with reduced number of trials, resulting in the following 7 blocks: Good/bad discrimination (12 trials), self/others discrimination (12 trials), first paired ( 24 trials), second paired ( 24 trials), good/bad discrimination reversed (24 trials), first reversed paired (24 trials), second reversed paired (24 trials). The number of trials in the reversed good/bad discrimination block was doubled to reduce the impact of task order, as recommended by Nosek, Greenwald, and Banaji (2005), thus resulting in 24 trials. During the inter-trial-interval of $400 \mathrm{~ms}$, a fixation cross appeared in the center of the screen. In case of an erroneous response, a red "?" appeared below the stimulus until the correct response was provided. The IAT was performed using Presentation ${ }^{\circledR}$ software (Version 18.1, Neurobehavioral Systems, Inc., Berkeley, CA, www.neurobs.com). The 'd' and '\#’ buttons of a standard German keyboard were employed as response buttons. 